\title{
Understanding communication between emergency and consulting physicians: a qualitative study that describes and defines the essential elements of the emergency department consultation-referral process for the junior learner
}

\author{
Teresa Chan, $\mathrm{MD}^{*}$; Donika Orlich, $\mathrm{MD}^{*}$; Kulamakan Kulasegaram, $\mathrm{BHSc}^{\dagger}$; Jonathan Sherbino, $\mathrm{MD}, \mathrm{MEd}^{*}$
}

\section{ABSTRACT}

Objectives: To define the important elements of an emergency department (ED) consultation request and to develop a simple model of the process.

Methods: From March to September 2010, 61 physicians (21 emergency medicine [EM], 20 general surgery [GS], 20 internal medicine [IM]; 31 residents, 30 attending staff) were questioned about how junior learners should be taught about ED consultation. Two investigators independently reviewed focus group and interview transcripts using grounded theory to generate an index of themes until saturation was reached. Disagreements were resolved by consensus, yielding an inventory of themes and subthemes. All transcripts were coded using this index of themes; $30 \%$ of transcripts were coded in duplicate to determine the agreement.

Results: A total of 245 themes and subthemes were identified. The agreement between reviewers was $77 \%$. Important themes in the process were as follows: initial preparation and review of investigations by EM physician (overall endorsement $87 \%$ [range $70-100 \%$ in different groups]); identification of involved parties (patient and involved physicians) (100\%); hypothesis of patient's diagnosis (75\% [range $62-83 \%$ ]) or question for the consulting physician (70\% [range 55-95\%]); urgency (100\%) and stability (74\% [range $62-80 \%]$ ); questions from the consultant $(100 \%)$; discussion/communication (98\% [range 95-100\%]); and feedback (98\% [range 95-100\%]). These components were reorganized into a simple framework (PIQUED). Each clinical specialty significantly contributed to the model $\left(\chi^{2}=7.9 ; p\right.$ value $=0.019$ ). Each group contributed uniquely to the final list of important elements (percent contributions: EM, 57\%; GS, 41\%; IM, 64\%).

Conclusions: We define important elements of an ED consultation with input from emergency and consulting physicians. We propose a model that organizes these elements into a simple framework (PIQUED) that may be valuable for junior learners.

\section{RÉSUMÉ}

Objectif: L'étude visait à définir les éléments importants des demandes de consultation aux services d'urgence (SU) et à élaborer un modèle simple du processus.

Méthode: De mars à septembre 2010, nous avons posé des questions à 61 médecins (21 urgentologues [urg.], 20 chirurgiens généristes [CG], 20 internistes [int.], 31 résidents, et 30 médecins titulaires) sur la façon dont il faudrait enseigner le processus de consultation aux SU aux jeunes apprenants. Deux chercheurs ont examiné, chacun de leur côté, les transcriptions des groupes de discussion et des entrevues à l'aide de la théorie ancrée dans des données empiriques afin de générer un index de thèmes jusqu'à I'atteinte du point de saturation. Les divergences de points de vue ont été réglées par consensus, ce qui a donné lieu finalement à la formation d'un corpus de thèmes et de sousthèmes. Toutes les transcriptions ont été codées en fonction de cet index de thèmes; $30 \%$ des transcriptions ont été codées en double afin de déterminer le degré de convergence.

Résultats: Au total, 245 thèmes et sous-thèmes se sont dégagés de l'exercice. Le degré de convergence entre les

From the *Division of Emergency Medicine, Department of Medicine, and Health Research Methods Program, McMaster University, Hamilton, ON.

This work was presented in abstract form at the Canadian Association of Emergency Physicians (CAEP) Conference 2011, St. John's, Newfoundland, and the International Conference on Residency Education (ICRE) 2011, Quebec City.

Correspondence: Dr. Teresa M. Chan, McMaster Clinics Room 254, 247 Barton Street East, Hamilton, ON L8L 2X2; teresa.chan@medportal.ca. This article has been peer reviewed. 
examinateurs était de $77 \%$. Les thèmes importants du processus se sont établis comme suit: préparation et revue de l'exploration initiale par l'urgentologue (appui global: $87 \%$ [plage: $70-100 \%$ dans différents groupes]); détermination des parties intéressées (patient et médecins concernés) (100\%); hypothèse sur le diagnostic (75\% [plage: $62-83 \%$ ]) ou question à l'intention du médecin consultant (70 \% [plage: 55-95\%]); urgence (100\%) et stabilité (74\% [plage: $62-80 \%$ ]); questions du médecin consultant (100\%); discussion/communication (98 $\%$ [plage: 95-100 \%]); et rétroaction (98\% [plage: 95-100\%]). Ces éléments ont été réorganisés en une structure simple (PIQUED). Chaque spécialité clinique a joué un rôle important dans I'élaboration du modèle $\left(\chi^{2}=7.9\right.$; valeur $\left.p=0.019\right)$, et chaque groupe a participé de manière particulière à l'élaboration de la liste définitive des éléments importants (pourcentage de participation: urg., 57 \%; CG, $41 \%$; int., 64 \%).

Conclusions: Nous avons défini les éléments importants du processus de consultation aux SU à partir de suggestions faites par des urgentologues et des médecins consultants et avons proposé un modèle d'organisation de ces éléments en une structure simple (PIQUED), susceptible d'être très utile aux jeunes apprenants.

Keywords: communication, consultants, emergency medicine, interphysician communication, referral and consultation
Consultations and referrals are an integral aspect of physician practice. For emergency physicians in North America, the consultation rate is approximately 38 to $40 \%$, including both inpatient and outpatient referrals. ${ }^{1,2}$ A systematic review revealed that there is a preponderance of opinion-based literature on this topic. ${ }^{3}$ To date, only one other study has attempted to clarify the specifics of the consultation process, ${ }^{4}$ and no study to date has specifically incorporated the views of residents in such an endeavour.

The purpose of this study was to determine the key elements of an emergency department (ED) consultation request and to use this information to develop an explanatory model to assist junior learners in understanding the process.

\section{METHODS}

\section{Study design}

This was a mixed-methods study that used semistructured interviews or semistructured moderated focus group discussions. Approval was granted by the Faculty of Health Sciences/McMaster University Research Ethics Board. All participants provided written, informed consent.

\section{Study setting and population}

Our setting was the four academic teaching hospitals in Hamilton, Ontario. A convenience sample of resident and attending physicians from three services (emergency medicine $[\mathrm{EM}]$, general surgery [GS], internal medicine $[\mathrm{IM}]$ ) was solicited through e-mail via a modified Dillman approach. ${ }^{5}$ Recruitment requests were sent via e-mail to eligible faculty and residents.
A convenience sample of approximately 10 volunteers from each subgroup was recruited: 11 EM residents from a pool of 23 approached; the first 10 EM attending physicians from a pool of 67 approached; all 10 internists approached; and 10 general surgeons from a pool of 23 approached. Attending interviews were conducted in a one-on-one format, whereas resident questioning was conducted in focus groups of up to eight participants. All residents had completed at least their first year of residency (i.e., had to be at least in the second year of residency) and had to have worked in the ED environment (either as an EM resident or a resident performing ED consultations) within the last 12 months. Attending physicians had to have practiced on inpatient teams while taking ED consultation requests or in the ED within 6 months of the interview or focus group.

\section{Study protocol}

The interview template was based on input from content experts and then piloted on a small sample of nonparticipating faculty members and residents. See Appendix 1 for the questions asked of both emergency and consulting physicians. Pilot participants' feedback was incorporated into the question list.

During a 6-month period from March to September 2010 , interview and focus groups were conducted. The interviews or focus groups lasted between 20 and 96 minutes. These interviews were recorded, transcribed, and deidentified prior to analysis.

\section{Data analysis}

The transcripts of the interviews were analyzed using grounded theory principles. ${ }^{6-9}$ Transcripts were independently reviewed by two investigators (T.C., D.O.) 
to create a single registry of codes until a saturation point was reached and no new codes were generated. Each list of codes was continuously and iteratively reviewed and merged by consensus into a final master registry. The complete data set was then coded by a single investigator using the master registry, producing an inventory of themes that comprise an ED referral.

Thirty percent of transcripts were coded by two investigators using the master code. The agreement was calculated between the coded transcripts. Disagreements were resolved by consensus.

The frequency of themes was calculated and analyzed. From each unique group, all items with over 60\% endorsement were considered "important themes" and used for further analyses. We triangulated our findings further through comparison with other studies in the area. ${ }^{4,10}$

\section{Statistical analysis}

To detect differences in priorities, the proportion endorsing "important themes" was compared across specialties and across levels of seniority using the Pearson chi-square test. All analyses were performed with SPSS version 17 (SPSS Inc, Chicago, IL).

\section{RESULTS}

Sixty-one participants were recruited. Table 1 shows the demographics for the study participants. The average age of residents was 29.5 years, and the average age of attending physicians was 42.7 years. Males comprised $67 \%$ of the group. Forty transcripts (30 interviews of attending physicians; 10 focus groups) were coded, yielding 245 data points.
The agreement between the two investigators was $77 \%$. There were 46 important themes, which were categorized into four key components and two modifiers. Components were defined as themes around content or substantive elements that added to the structure of consultation requests. Modifiers were subthemes that altered the behaviours of either the emergency physician or the consulting physician during the consultation process.

Table 2 shows the important themes endorsed by each specialty group; Appendix 2 shows the important themes endorsed by residents versus attending physicians. Overall, the elements determined as "important" for the referral-consultation process were as follows:

1. Components (substantive elements that added to the structure of consultation requests):

a. Initial preparation and review of initial work (e.g., investigations, management) (87\% [ranging from 70 to $100 \%$ in different groups])

b. Clinical communication about involved parties $(100 \%)$, including identification of involved parties such as the physicians and informing consulting physicians about the patient (100\%) and the patient's clinical case $(100 \%)$

c. Questions (100\%), including the clinical question for the consulting physician $70 \%$ [range $55-95 \%]$ ), hypothesis of the patient's diagnosis (75\% [range 62-83\%]), and anticipating questions that might be asked by the consulting physician (84\% [range 70-85\%])

d. Discussion after the referral (98\% [range 95$100 \%]$ ), including topics such as giving feedback about the patient's progress $(98 \%$ [range 95-100\%]), closing the loop (68\% residents), feeding back to addressing mistakes (69\%

\begin{tabular}{|c|c|c|c|c|}
\hline Level of training & Overall & EM participants & GS participants & IM participants \\
\hline Residents & 31 & 11 & 10 & 10 \\
\hline Attending staff & 30 & 10 & 10 & 10 \\
\hline Average age (yr) & 36 & 35.2 & 38 & 35.5 \\
\hline Residents & 29.5 & 30.5 & 29 & 29.2 \\
\hline Attending staff & 42.7 & 40.2 & 47 & 41.1 \\
\hline Gender (\%) & $67 \mathrm{M}$ & 62 & 70 & 65 \\
\hline Residents & $61 \mathrm{M}$ & 64 & 60 & 60 \\
\hline Attending staff & $70 \mathrm{M}$ & 60 & 80 & 70 \\
\hline
\end{tabular}


Table 2. Important themes and subthemes and their endorsement by specialty group

\begin{tabular}{|c|c|c|c|c|}
\hline \multirow[b]{2}{*}{ Theme/subtheme } & \multirow[b]{2}{*}{$\begin{array}{l}\text { Overall frequency } \\
\qquad \%)(n=61)\end{array}$} & \multicolumn{3}{|c|}{ Comparing by specialty: EM to consultants (GS, IM) (\%) } \\
\hline & & $\begin{array}{l}\text { Most frequent EM } \\
\text { themes }(n=21)\end{array}$ & $\begin{array}{l}\text { Most frequent GS } \\
\text { themes }(n=20)\end{array}$ & $\begin{array}{l}\text { Most frequent IM } \\
\text { themes }(n=20)\end{array}$ \\
\hline Initial EM preparation & 87 & 100 & 70 & 90 \\
\hline Investigations & 51 & & 60 & \\
\hline EP reviews & 52 & 91 & & \\
\hline $\begin{array}{l}\text { Clinical communication about parties } \\
\text { involved (physicians and patient) }\end{array}$ & 100 & 100 & 100 & 100 \\
\hline ID of yourself & 98 & & 95 & 100 \\
\hline By your name & 84 & 100 & 75 & 85 \\
\hline Rank (resident, AP) & 75 & 91 & 65 & 80 \\
\hline Resident's service/AP & 34 & 81 & & \\
\hline Identify colleague & 75 & & 65 & 80 \\
\hline Let others introduce themselves & 43 & 81 & & 65 \\
\hline Identification of patient & 82 & & 75 & 75 \\
\hline Priority/stability & 64 & 95 & & 75 \\
\hline EP's hypothesis re: diagnosis & 75 & 67 & 80 & 85 \\
\hline Pertinent clinical findings & 93 & 62 & 100 & 100 \\
\hline Current vital signs & 28 & 81 & & 60 \\
\hline Summary of investigations & 56 & & 60 & 65 \\
\hline Confirms consultant will see patient & 59 & 62 & 75 & \\
\hline Questions & 98 & 95 & 100 & 100 \\
\hline Clinical question from EP & 70 & 95 & & 60 \\
\hline Reason for referral & 54 & 71 & & \\
\hline Timing of questions & 84 & 62 & & 100 \\
\hline After the EP finishes & 52 & & & 70 \\
\hline Intercalated throughout encounter & 44 & & 65 & 65 \\
\hline $\mathrm{CP}$ asks questions & 84 & 86 & 70 & 95 \\
\hline To clarify missing information & 64 & & 60 & 75 \\
\hline To ask more about patient & 46 & & & 65 \\
\hline EP asks questions & 57 & 76 & & \\
\hline Discussion after the referral & 98 & 95 & 100 & 100 \\
\hline Feedback & 98 & 95 & 100 & 100 \\
\hline Closing the loop & 59 & & 60 & 65 \\
\hline EP displayed interest & 67 & & & 75 \\
\hline To address/warn about a mistake & 69 & & & 80 \\
\hline CP thought EP would like to know & 49 & & & 80 \\
\hline To educate EP & 66 & & & 70 \\
\hline To improve the process & 62 & & & 70 \\
\hline To ask more information & 39 & & & 60 \\
\hline Urgency expressed & 100 & 100 & 100 & 100 \\
\hline Need directness for urgent case & 64 & & 85 & 70 \\
\hline States concern using verbal cues & 74 & 62 & 80 & 80 \\
\hline Uses trigger words for urgent case & 74 & 62 & 70 & 70 \\
\hline More information is needed on urgent case & 77 & 71 & 70 & 90 \\
\hline Details on management initiated & 48 & & & 70 \\
\hline $\mathrm{CP}$ acts when hearing urgent case & 43 & 71 & & \\
\hline $\mathrm{CP}$ attends quickly & 39 & 67 & & \\
\hline Educational modifications & 80 & 100 & 80 & 60 \\
\hline To teach around the case & 80 & 100 & 80 & 60 \\
\hline $\mathrm{CP}$ gives feedback to EM learner & 74 & 71 & 70 & 80 \\
\hline EP supervises juniors making referrals & 72 & 100 & 70 & \\
\hline EP observes learner & 26 & 62 & & \\
\hline
\end{tabular}




\begin{tabular}{|c|c|c|c|c|}
\hline \multirow[b]{2}{*}{ Theme/subtheme } & \multirow[b]{2}{*}{$\begin{array}{l}\text { Overall frequency } \\
\quad(\%)(n=61)\end{array}$} & \multicolumn{3}{|c|}{ Comparing by specialty: EM to consultants (GS, IM) (\%) } \\
\hline & & $\begin{array}{l}\text { Most frequent EM } \\
\text { themes }(n=21)\end{array}$ & $\begin{array}{l}\text { Most frequent GS } \\
\text { themes }(n=20)\end{array}$ & $\begin{array}{l}\text { Most frequent IM } \\
\text { themes }(n=20)\end{array}$ \\
\hline EP gives feedback & 49 & 81 & & \\
\hline $\begin{array}{l}\text { Altering expectations based on involvement } \\
\text { of learner* }\end{array}$ & 54 & & & \\
\hline
\end{tabular}

[range $67-71 \%$ ]), and feeding back to educate the emergency physician (80\% IM)

2. Modifiers (subthemes that altered the behaviours of either the emergency or consulting physician):

a. Urgency of the consultation (100\%) and patient stability (74\% [range 62-80\%])

b. Educational modifications (72\% [range 45$100 \%]$ ), such as teaching around the case ( $80 \%$ [range $60-100 \%]$ ), the supervision of the learner making the consultation by the emergency physician $(62 \% \mathrm{EM})$, and the incorporation of teaching from the consulting physician to the junior EM learner (74\% [range 61-87\%])

\section{Differences between clinical specialties}

There was a significant difference between the three specialties in their endorsement of important codes $\left(\chi^{2}=7.9, \mathrm{df}=1, p=0.02\right)$. The differences in distribution between residents and attending physicians were also found to be statistically significant $\left(\chi^{2}=11.8, \mathrm{df}=1, p=0.001\right)$. These findings suggest that all specialties, residents, and attending physicians uniquely contributed to the final model. The percentage of contributions to the final index of themes by each specialty was EM, 57\%; GS, 41\%; and IM, 64\%.

Specifically, the GS group differed from the IM group in the proportion of endorsement for important codes $\left(\chi^{2}=9.9, \mathrm{df}=1, p=0.002\right)$. Some examples of differences included providing feedback from consulting physicians to EM (70\% GS v. 45\% IM) and the necessity of summarizing all the investigations and management (100\% IM v. $70 \%$ GS). EM physicians' lists of important codes did not vary significantly with those of the GS or IM group $(p=0.46$ and 0.08 , respectively), suggesting that EM physicians may tailor their approach depending on the consultant service. Our study revealed that both consulting physicians $(100 \%)$ and emergency physicians $(95 \%)$ value some aspect of feedback.

With regard to the urgency of the consultation, both emergency and consulting physicians commented on using verbal cues to express urgency during the consultation (62\% EM, 80\% GS/IM). Most consulting physicians $(72 \%)$ stated that EM physicians should be direct with regard to the urgency of a consultation. Emergency physicians (67\%) expected prompt attendance of the consulting physician when hearing abouturgent features of a case, whereas only $25 \%$ of consulting physicians explicitly stated that they would respond in such a fashion. The most important information sought by consulting physicians is the ED management completed or in progress (60\% GS/IM).

\section{Differences between attending and resident physicians}

Most attending physicians $(60 \%)$ stated that expectations must be altered when dealing with a learner during the consultation process. A majority of attending physicians $(72 \%)$ suggested that feedback to EM learners regarding their referral approach should come from EM supervisors. However, most attending physicians $(73 \%)$ felt that the consulting physician could also provide feedback. A majority of respondents (both residents and attending physicians) indicated that a senior physician should assume a teaching role with respect to the consultation request (100\% EM, 70\% GS, 45\% IM) when a junior learner is involved.

\section{DISCUSSION}

This study is the first to use resident input to define an effective ED consultation that incorporates the 
perspectives of those requesting the consultation [EM physicians] and those receiving them [GS and IM physicians]. Each group contributed different amounts to the common list of important elements of the referral process (percent contributions: EM, 57\%; GS, $41 \%$; IM, 64\%), which suggests that each group helps elucidate a unique aspect of the consultation process.

\section{Main components}

The themes and subthemes endorsed by the majority of respondents formed the consultation model shown in Figure 1. Highly endorsed themes and subthemes were grouped into four components and two modifiers that describe the consultation model (see Figure 1).

The main components noted in our study are consistent with other literature surrounding the transfer of care of patients from the emergency physician to the admitting physician. ${ }^{4,10}$ However, this study offers new insight into how learners affect this process. In their 5C's model, Kessler and colleagues describe similar components to the consultation process, namely Contact, Communicate, Core question, Collaboration, and Closing the loop. ${ }^{4}$ The main components we identified in our study were similar but extend the framework to include particular behaviours important for junior learners in the ED, such as preparation (i.e., the initial workup, management, and review of key findings) and anticipating questions from consulting physicians.

The consultation conversation is not a simple oneway "handover" conversation as previously described. ${ }^{11}$ Encounters may revolve around topics such as accepting responsibility, deciding on required investigations and further management for a particular case, and timing of the arrival of the consulting physician. Thus, interactions through questions and feedback after the initial referral were endorsed by all parties ( $98 \%$ total) as essential. Likewise, feedback was desired by all interviewed residents (100\%), including EM residents (100\%). This finding is consistent with that of a previous study. ${ }^{12}$

\section{Modifiers}

Our study differs from previous literature in the exploration of two unique situations that necessitate changes in the consultation structure. ${ }^{3,4,10}$ Our results suggest that emergency physicians make modifications to the consultation process when they need to express the urgency of a case to the consulting physician. Also, emergency physicians tend to make modifications to the consultation process when junior learners are included. Such changes include teaching around the

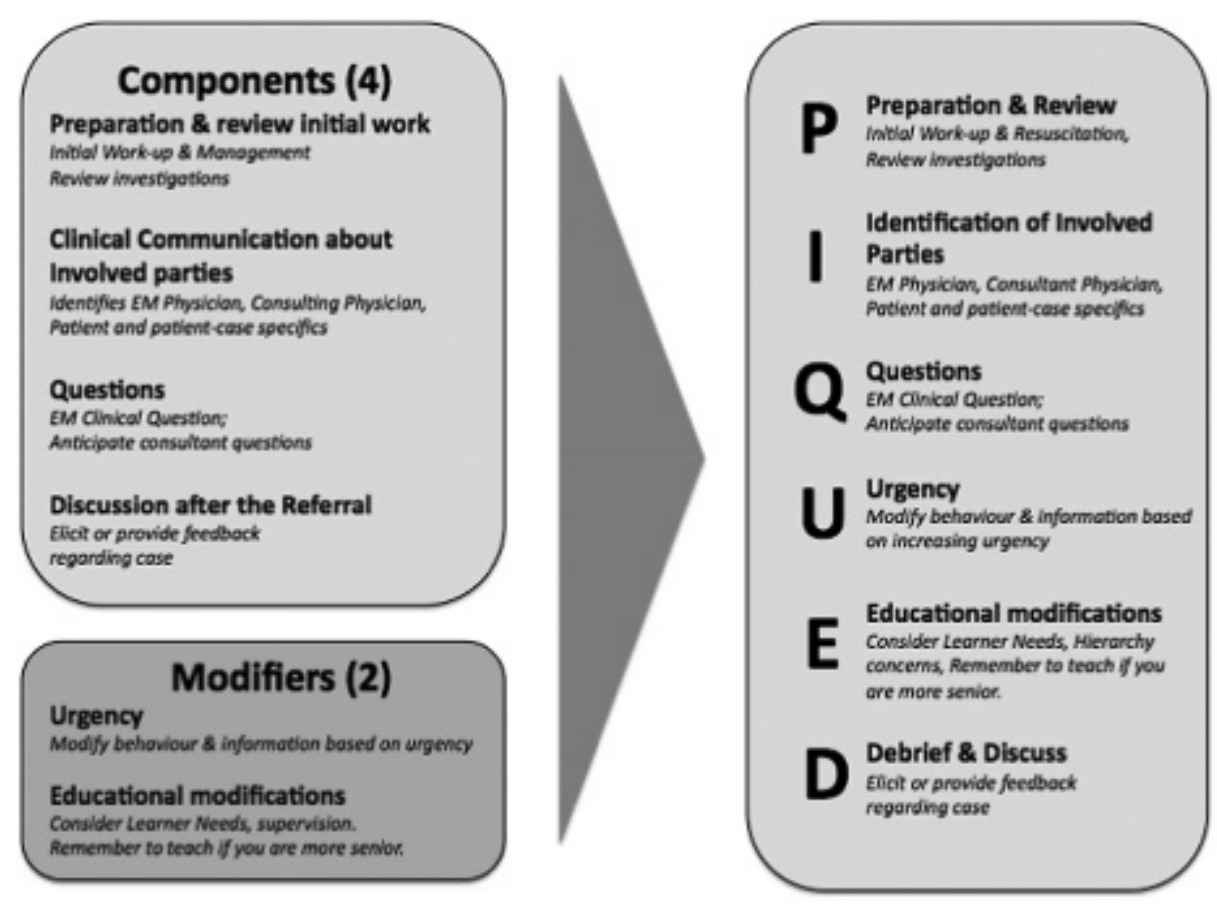

Figure 1. The PIQUED framework. The key elements (four components and two modifiers) are reassembled into a simple mnemonic to assist learners in conceptualizing the referral and consultation process. 
case, observing the learner request the consultation, and providing feedback regarding their initial investigations and management.

\section{Stages of development}

One of the most interesting findings from our study is that there was a statistical difference $(p=0.001)$ between the resident and attending groups' lists of important themes (i.e., subthemes that altered the behaviours of either the emergency or the consulting physician). This suggests that the optimal consultation request differs between residents and attending physicians, which may impact communication between these two groups. Furthermore, such differences may reflect a developmental change in thought processes regarding consultation requests that occur throughout residency. This finding may also reflect differences expected of more junior learners versus their more senior counterparts.

\section{Model}

Figure 1 shows the translation of the themes (four components and two modifiers) into a simple model that may be of benefit to junior learners without considerable experience in ED consultations.

\section{LIMITATIONS OF THIS STUDY}

Due to operational feasibility, this study involved a single academic faculty of medicine and a convenience sample of willing volunteers. The residents were interviewed in focus groups because of limitations in resources (single interviewer). We attempted to interview residents of similar years to prevent issues around hierarchy; however, an inherent problem with focus groups is self-censorship by participants because of social influences. There are, however, advantages of focus groups such as increased discussion (which can reveal other unexpected and deeper examination of topics) and discourse and decreased researcher resources.

The generalizability of the consultation framework described may be different in community, nonteaching hospitals. We derived this model from interviews with the question of how best to teach junior learners. Additionally, the interviewer and coders were all emergency physicians, which may have resulted in inadequate metaposition (i.e., analytical distance) from the subject matter.

\section{FUTURE DIRECTIONS}

This work lends itself to further study in two areas: educational impact and patient outcomes. There has been ample use of mnemonics for providing frameworks to teach learners about complex processes (e.g., SPIKES, SEGUE, 5C's) ${ }^{4,13,14}$; however, the underlying learning processes behind these and whether they are the best way to teach complex skills is not well studied. Further study will be required to determine whether mnemonic-based frameworks have the intended and lasting educational impact on learners.

\section{CONCLUSIONS}

Our research suggests that referral-consultation is a complex relationship. We present an evidence-based model for consultations from academic centre EDs that should include these key elements: preparation and the initial EM management; identifying the parties involved (the patient and physicians); incorporating/ anticipating questions; and debriefing and discussion after the referral. Acknowledging situations that modify a consultation (urgency and educational considerations for involved learners) is also important. Together these elements form a framework (the PIQUED framework) that may be used to help junior learners conceptualize the complex process of ED consultation requests.

Acknowledgements: We would like to thank Gerson Mobo and Sarah Compeau for their assistance with the transcription process. We would also like to thank Drs. John Crossley, Douglas Wright, and Claire Kenny-Scherber for their assistance in the initial survey construction.

Competing interests: This work was supported by a research grant from the Canadian Association of Emergency Physicians. The lead author was also the recipient of the Royal College of Physicians and Surgeons of Canada's Fellowship for Studies in Medical Education.

\section{REFERENCES}

1. Woods RA, Lee R, Ospina MB, et al. Consultation outcomes in the emergency department: exploring rates and complexity. Can 7 Emerg Med 2008;10:25-31.

2. Cortazzo JM, Guertler AT, Rice MM. Consultation and referral patterns from a teaching hospital emergency department. Am 7 Emerg Med 1993;25:456-60, doi:10.1016/ 0735-6757(93)90082-M.

3. Lee RS, Woods R, Bullard M, et al. Consultations in the emergency department: a systematic review of the literature. 
Can 7 Emerg Med 2008;25:4-9, doi:10.1136/emj.2007. 051631 .

4. Kessler CS, Kutka BM, Badillo C. Consultation in the emergency department. A qualitative analysis and review. 7 Emerg Med 2012;42:704-11. Epub 2011 May 26.

5. Dillman DA. Mail and Internet surveys: the Tailored Design Method 2007 update with new Internet, visual, and mixed-mode guide. Hoboken (NJ): John Wiley \& Sons; 2007.

6. Charmaz K. Constructing grounded theory: a practical guide through qualitative analysis. 2nd ed. Rohnert Park, (CA): Sage; 2006.

7. Bandiera GL, Lee S, Tiberius R. Creating effective learning in today's emergency departments: how accomplished teachers get it done. Ann Emerg Med 2005;45:253-61, doi:10.1016/j.annemergmed.2004.08.007.

8. Flick U. An introduction to qualitative research. 2nd ed. Thousand Oaks (CA): Sage; 2002.

9. Silverman DK, Lincoln YS, editors. Analyzing talk and text. The handbook of qualitative research. Thousand Oaks (CA): Sage; 2001. p. 821-34.

10. Wright D, Kenny-Scherber C, Patel A, et al. Defining and optimizing collaboration between emergency medicine and internal medicine physicians. Can 7 Gen Intern Med 2011;6: 28-9.

11. Matthews AL, Harvey CM, Schuster RJ, Durso FT. Emergency physician to admitting physician handovers: an exploratory study. In: Proceedings of the Human Factors and Ergonomics Society Annual Meeting. Vol 46, No 16. Sage; 2002. p. 1511-15.

12. Florence RSK, Garneti N, Burchett N. Closing the loop: feedback to accident and emergency SHOs on their referrals to hospital specialists. Ann R Coll Surg Engl 2003;85:192-4, doi:10.1308/003588403321661370.

13. Baile WF, Buckman R, Lenzi R, et al. SPIKES-a six-step protocol for delivering bad news: application to the patient with cancer. The Oncologist 2000;5:302-11.

14. Makoul G. The SEGUE framework for teaching and assessing communication skills. Pat Educ Couns 2001;45:2334, doi:10.1016/S0738-3991(01)00136-7.

\section{APPENDIX 1: MAIN QUESTION PROMPTS USED IN FOCUS} GROUPS OR INTERVIEWS

\section{Questions for emergency physicians}

What are the essential parts of a good emergency medicine consultation request?

What are the other techniques that you use to facilitate an effective consultation delivery/referral reception?
What information do you think is important to convey during the initial referral-consultation encounter?

What is the role of asking questions during the initial referral-consultation encounter?

What do you expect with urgent or emergent cases?

What would you consider is the satisfactory conclusion to the conclusion of your initial consultation/ referral encounter?

Do you ever give or receive feedback regarding your initial referral-consultation encounter with the consulting physician?

What are the impediments to a good referralconsultation encounter?

How do pre-existing relationships affect the consultation process?

How do you cope or compensate for these impediments?

\section{Questions for consulting physicians}

What are the essential parts of a good emergency medicine consultation request?

What are the other techniques that you use to facilitate an effective referral-consultation encounter?

What information do you think is important to convey during the initial referral-consultation encounter?

What is the role of asking questions during the initial referral-consultation encounter?

What do you expect with urgent or emergent cases?

What would you consider is the satisfactory conclusion to the conclusion of your initial referralconsultation encounter?

Do you ever give or receive feedback regarding your initial referral-consultation encounter?

What are the impediments to a good consultationreferral encounter?

How do pre-existing relationships affect the consultation process?

How do you cope or compensate for these impediments? 


\section{Appendix 2. Important themes and subthemes and their endorsement by rank}

\begin{tabular}{|c|c|c|}
\hline \multirow[b]{2}{*}{ Theme/subtheme } & \multicolumn{2}{|c|}{ Comparing by rank: residents to APs (\%) } \\
\hline & Most frequent resident themes $(n=31)$ & Most frequent attending themes $(n=30)$ \\
\hline $\begin{array}{l}\text { Initial EM preparation } \\
\text { Investigations }\end{array}$ & 90 & 83 \\
\hline EP reviews & 65 & \\
\hline $\begin{array}{l}\text { Clinical communication about parties involved } \\
\text { (physicians and patient) }\end{array}$ & 100 & 100 \\
\hline ID of yourself & 97 & 100 \\
\hline By your name & 74 & 93 \\
\hline Rank (resident, AP) & 84 & 67 \\
\hline Resident's service/AP & 68 & \\
\hline \multicolumn{2}{|l|}{ Let others introduce themselves } & 90 \\
\hline Identification of patient & 87 & 77 \\
\hline Priority/stability & 65 & 63 \\
\hline EP's hypothesis re: diagnosis & 81 & 70 \\
\hline \multicolumn{3}{|l|}{ Current vital signs } \\
\hline Summary of investigations & & 60 \\
\hline Confirms consultant will see patient & & 60 \\
\hline Questions & 97 & 100 \\
\hline Clinical question from EP & 65 & 77 \\
\hline Reason for referral & & 60 \\
\hline Timing of questions & 94 & 73 \\
\hline $\begin{array}{l}\text { After the EP finishes } \\
\text { Intercalated throughout encounter }\end{array}$ & Intercalated throughout encounter & \\
\hline $\mathrm{CP}$ asks questions & 87 & 80 \\
\hline To clarify missing information & 65 & 63 \\
\hline \multicolumn{3}{|l|}{ To ask more about patient } \\
\hline EP asks questions & & 63 \\
\hline Discussion after the referral & 100 & 97 \\
\hline Feedback & 100 & 97 \\
\hline Closing the loop & & 63 \\
\hline EP displayed interest & 77 & \\
\hline To address/warn about a mistake & 71 & 67 \\
\hline \multicolumn{3}{|l|}{ CP thought EP would like to know } \\
\hline To educate EP & 71 & 60 \\
\hline To improve the process & 65 & 60 \\
\hline \multicolumn{3}{|l|}{ To ask more information } \\
\hline Urgency expressed & 100 & 100 \\
\hline Need directness for urgent case & & 73 \\
\hline States concern using verbal cues & 81 & 67 \\
\hline Uses trigger words for urgent case & 77 & \\
\hline \multicolumn{3}{|l|}{ Details on management initiated } \\
\hline \multicolumn{3}{|l|}{$\mathrm{CP}$ acts when hearing urgent case } \\
\hline \multicolumn{3}{|l|}{$\mathrm{CP}$ attends quickly } \\
\hline Educational modifications & 74 & 87 \\
\hline To teach around the case & 74 & 87 \\
\hline $\mathrm{CP}$ gives feedback to EM learner & 61 & 87 \\
\hline EP supervises juniors making referrals & 68 & 77 \\
\hline \multicolumn{3}{|l|}{ EP observes learner } \\
\hline EP gives feedback & & \\
\hline
\end{tabular}


Essential elements of ED referrals and consultations

Appendix 2. Continued

Comparing by rank: residents to APs (\%)

Theme/subtheme

Most frequent resident themes $(n=31)$

Most frequent attending themes $(n=30)$

Altering expectations based on involvement of learner*

$\mathrm{AP}=$ attending physician; $\mathrm{CP}=$ consulting physician; $\mathrm{EM}=$ emergency medicine; $\mathrm{EP}=$ emergency physician

Each group shows only the statistics for any theme or subtheme that was deemed most frequent (reaching $60 \%$ frequency). All items on this final list reached $60 \%$ endorsement by one of two subgroups (attending physicians, resident physicians). 